\title{
SUJEITO MULHER: A IMAGEM DA BELEZA
}

\author{
Woman Subject: The Image of Beauty \\ Sujeto Mujer: La imagen de la Belleza \\ Le sujet Femme: L'image de la Beauté
}

Artigo Original

\begin{abstract}
Resumo
Na pós-modernidade, o espetáculo rege as relações sociais. A mídia veicula imagens, sobretudo por intermédio da televisão, que no Brasil é o meio de comunicação em massa mais difundido. Além disso, a mídia é uma instância formadora de sujeitos: homens e mulheres. É incontestável haver diferenças biológicas entre homens e mulheres. Ademais, a cultura ocidental, ao longo dos tempos designou posições sociais específicas a eles. A partir do século XIX, através do paradigma da diferença sexual os processos de subjetivação masculinos e femininos foram tratados de forma diferente. Porém, a lógica masculina de subjetivação continua a ser tratada enquanto paradigma universal. Além disso, a beleza é considerada um importante atributo na construção da subjetividade feminina. Nosso objetivo é investigar a formação subjetiva da mulher através da beleza, enviesada pela sociedade do espetáculo, e pelas postulações psicanalíticas, sobretudo de Freud. Nesse artigo, propomos dissertar sobre a possibilidade da mulher pós-moderna se tornar sujeito através do espetáculo e através da beleza. Assim, compreendemos que a subjetividade feminina, referenciada pela lógica fálica, está inscrita na condição de "buscar o que lhe falta", e que a beleza é compreendida como um atributo fálico compensatório à castração feminina, usado para proporcionar à mulher a possibilidade de manter-se na condição de "ser olhada pelo outro".
\end{abstract}

Palavras-chave: mulher; imagem; psicanálise; beleza; subjetividade.

\begin{abstract}
During postmodernity, the spectacle rules the social relations. The media transmit broadcast, especially through television, the most popular mass media in Brazil. Besides, the media is a subject's former instance: men and women. It is unquestionable to have biological distinction between men and women. However, the western culture, over the time designated specific social positions to them. From the XIX century, through the sexual distinction paradigm the men's and women's process of subjectivation were treated like different. However, the subjectivation men's logic to still be treated like universal paradigm. Besides, the beauty is considered an important attribute on the woman's subjectivity construction. Our aim is to investigate the woman's subjective formation through beauty, biased spectacle's society, and Psychoanalytic postulations, on Freud. On this article, we propose to discourse about the postmodernity woman's chance becomes subject through spectacle and beauty. Like that, we understand is enrolled the woman's subjective, referencing to falocentrism, in "to search that without" condition, and the beauty is understanding like a compensate falocentrism's attribute to woman's castration, used to afford to woman the possibility of to keep herself on "to be watched to other" condition.
\end{abstract}

Keywords: woman; image; psychoanalysis; beauty; subjective.

\section{Resumen}

En posmodernidad, el espectáculo rige las relaciones sociales. Los medios de comunicación transmiten imágenes y la televisión es la intermediaria. En Brasil esto es lo medio de comunicación más difundido. Además, los medios de comunicación son instancias formadoras de sujetos: hombres y mujeres. Es irrefutable haber diferencias biológicas entre hombres y mujeres. Entretanto, la cultura occidental, a lo largo de los tiempos señaló posiciones

\section{Christiane Moura Nascimento ${ }^{(1)}$ Luiz Carlos Avelino da Silva ${ }^{(2)}$}

1) Mestre em Psicologia Aplicada (Universidade Federal de Uberlândia, 2011). Graduada em Psicologia (Universidade Federal de Uberlândia, 2005). Atualmente é Coordenadora de SRT (Serviço Residencial Terapeutico) em São Paulo - SP.

2) Doutor em Psicologia Escolar e do Desenvolvimento Humano (Universidade de São Paulo, 2004). Mestre em Psicologia Clínica (Universidade de Brasília, 1993). Atualmente é professor da Universidade Federal de Uberlândia e atua em clínica e saúde mental.
Recebido em: 31/01/2012

Revisado em: 20/12/2014 Aceito em: 20/12/2014 
sociales especificas a ellos. A partir del siglo XIX, a través de lo paradigma de la diferencia sexual los procesos de subjetivación masculinos y femeninos fueron tratados de forma diferente. Sin embargo, la lógica masculina de subjetivación continúa a ser tratada mientras paradigma universal. Además de eso, la belleza es considerada un importante atributo en la construcción de la subjetividad femenina. Nuestro objetivo es investigar la formación subjetiva de la mujer a través de la belleza, atravesada por la sociedad del espectáculo, y por las postulaciones del psicoanálisis, sobre todo en Freud. En ese artículo, proponemos hacer una disertación sobre la posibilidad de la mujer posmoderna tornarse sujeto a través del espectáculo y de la belleza. Así, comprendemos que la subjetividad femenina, con referencia a la lógica fálica, está inscrita en la condición de "buscar lo que le falta", y que la belleza es comprendida como un atributo fálico que compensa a la mujer su castración, y es usado para proporcionar a ella la posibilidad de mantenerse en la condición de "ser mirada por el outro".

Palabras clave: mujer; imagen; psicoanálisis; belleza; subjetividad.

\section{Résumé}

Dans la postmodernité, le spectacle gouverne les relations sociales. Les médias véhiculent des images, surtout à travers la télévision, qui au Brésil est le moyen de communication de masse le plus diffusé. De plus, les médias sont une instance formatrice de sujets : des hommes et des femmes. Il est incontestable d'avoir des différences biologiques entre les hommes et les femmes. Toutefois, la culture occidentale, au cours du temps a désigné des positions sociales spécifiques pour eux. Depuis le XIXe siècle, à travers le paradigme de la différence sexuelle les processus de subjectivation masculins et féminins furent traités différemment. Cependant, la logique masculine de subjectivation est encore traitée comme un paradigme universel. De plus, la beauté est considérée comme un attribut important dans la construction de la subjectivité féminine. Notre objectif est d'investiguer la formation subjective des femmes à travers la beauté, biaisée par la société du spectacle et par les postulations psychanalytiques, notamment celles de Freud. Dans cet article, nous proposons d'argumenter sur la possibilité de la femme postmoderne devenir objet à travers le spectacle et à travers la beauté. Ainsi, nous comprenons que la subjectivité féminine, référencée par la logique phallique, est inscrite dans la condition de "chercher ce qui lui manque", et que la beauté est comprise comme un attribut phallique compensatoire à la castration féminine, utilisé pour offrir à la femme la possibilité de maintenir sur la condition "d'être regardée par l'autre".

Mots-clés: femme; image; la psychanalyse; beauté; subjectivité.

Reza o ditado popular que "uma imagem vale mais do que mil palavras!" Na década de 1990, um comercial de refrigerantes foi veiculado pela televisão, e causou bastante impacto: um líquido era colocado num copo e depois o recipiente era focalizado pela câmera e se lia no rótulo: "óleo de fígado de bacalhau". O discurso da propaganda era o seguinte: "Imagem não é nada. Sede é tudo. Obedeça a sua sede". Apesar de o comercial usar um discurso de redução à importância da imagem, não fossem as palavras escritas no rótulo do produto, o telespectador poderia ter ficado muito mais tempo com vontade de saborear o tal líquido derramado tão deliciosamente.

Sabe-se que o mundo das imagens se tornou fundamental nas atuais sociedades de massa. $\mathrm{O}$ ditado popular remete ao fenômeno cultural da prevalência das imagens no período pós-moderno. Entretanto há uma discussão entre alguns autores ligados ao campo das artes visuais no sentido de dizer que o momento pós-moderno é de "crise da imagem", tamanha a profusão de imagens em nosso cotidiano. De qualquer modo, as imagens se fazem enquanto realidades.

Espetáculo foi o nome cunhado por Debord (1997) para dizer do modo de funcionamento da sociedade pósmoderna: constituída através de imagens. "O espetáculo não é um conjunto de imagens, mas uma relação social entre pessoas, mediada pelas imagens" (Debord, 1997, p.14). O autor afirma que a sociedade do espetáculo emerge quando as relações sociais entre as pessoas começam a acontecer principalmente por intermédio de imagens. Seja como for, elas ocuparam um lugar de destaque central na cultura pósmoderna através do cinema, da televisão, do jornalismo, da publicidade e de outros meios de comunicação.

Baccega (2000) aponta que algumas pesquisas dizem que os meios de comunicação são o terceiro colocado na ocupação do tempo das pessoas, nas sociedades ocidentais industrializadas. O primeiro e o segundo colocados são o sono e o trabalho.

Desse modo, a mídia se tornou uma instância que ocupa a vida cotidiana dos sujeitos pós-modernos e está englobada na "indústria cultural", que representa o que é denominado como "cultura de massa".

Debord (1997) trata a mídia enquanto a "manifestação superficial mais esmagadora" do espetáculo. Vejamos:

Quando o mundo real se transforma em simples imagens, as simples imagens tornam-se seres reais e motivações eficientes de um comportamento hipnótico. O espetáculo, como tendência a fazer ver (por diferentes mediações especializadas) o mundo que já não se pode tocar diretamente, serve-se da visão como o sentido privilegiado da pessoa humana (...) (Debord, 1997, p.18).

O espetáculo cria condições de se fazer laços sociais entre os sujeitos predominantemente através do olhar, ou melhor, da visualidade: um que se mostra diante de um outro que assiste. Não se cria, dessa forma, espaço para o

\footnotetext{
1 Indústria cultural e cultura de massa são expressões cunhadas pela Escola de Frankfurt, que tem suas investigações direcionadas à análise crítica da cultura do século XX.
} 
diálogo (Debord, 1997).

Desse modo, podemos pensar que nossa cultura desenvolveu uma verdadeira tecnologia da imagem, a qual se produz pelo império da visualidade e do olhar. Podemos pensar na cultura da alta definição das imagens: nitidez, cores vivas, brilho, contraste, e etc. Toda uma parafernália tecnológica é constantemente criada e aperfeiçoada para tornar as imagens cada vez mais perfeitas, e consequentemente mais distantes da realidade vivenciada.

Como menciona Herrmann (1999, p.15) “(...) a realidade começou a perder credibilidade e, neste fim de século, já nos conformamos a que toda realidade seja tãosomente uma prodigiosa imagem virtual". Isso quer dizer que a realidade vivida e a realidade simulada ou ficcional já não se apresentam de modo a que se possa, com certeza, diferenciá-las. Na verdade, podemos pensar que o universo imagético transbordou para fora das telas e agora ocupa o cotidiano das relações humanas.

Podemos pensar que o espetáculo produz sujeitos que mais contemplam do que vivem, ou melhor, mais consomem suas contemplações. $\mathrm{Na}$ verdade, na pós-modernidade a vida passa a ser vista através das imagens. O homem pósmoderno se reconhece e compreende sua existência e seu desejo não através de suas próprias vivências, mas através das imagens que assiste. A vida começa a acontecer através das imagens.

A comunicação em massa, ou os mecanismos massmedia são uma forte expressão dessa nova cultura que se constitui diante do sujeito. Para Mira (2003) eles podem ser entendidos enquanto instâncias que constituem o atravessamento comum às diversas camadas populares, em sociedades marcadas por diferenças de classe, gênero, níveis socioeconômicos, diversidades geográficas e étnicas.

\section{Ser Imagem}

Com aparência estética e utilizando recursos de diversão e entretenimento a mídia atua na nossa constituição subjetiva. Além disso, ela se tornou um veículo de promoção dos laços sociais. Isso quer dizer que além da formação de subjetividade, a mídia constitui o sujeito em relação ao outro.

Kehl (2000) defende a ideia de que a mídia funciona como um Outro, no registro imaginário. Na verdade, a autora comenta que a relação entre sujeito e Outro possui um funcionamento primitivo, ao qual o "sujeito de desejo" só advém caso haja uma cessação ou uma falha nessa relação, no registro imaginário. Atentemo-nos às palavras da autora:

(...) o que acontece quando o Outro se encarna na produção de imagens da cultura, reconhecida por todos como lugar de saber e de satisfação dos desejos? Este Outro tornado para sempre imaginário representa ao mesmo tempo um poder e um saber sobre o sujeito - que então não tem mais que se indagar sobre o desejo, já que esse poder e esse saber estão dados de fora. Ao mesmo tempo, representa uma rivalidade, uma ameaça, porque é ameaçador que alguém saiba de nós antes de nós mesmos (...), antes que tenhamos possibilidade de criar alguma consistência subjetiva por meio da experiência com o real, dos tropeços e cabeçadas que o real nos faz dar. (Kehl, 2000, pp.143144)

A partir dessa ideia da autora podemos pensar que o sujeito pós-moderno se tornou predominantemente ancorado no imaginário. Nesse sentido, ele se torna insuficientemente simbólico e excessivamente imaginário. Ela denuncia que a contínua produção cultural de imagens, pela via do espetáculo, antecipa o sujeito e realiza, por ele, todo o trabalho de relação com o real. Assim, o sujeito está "perdido de suas referências simbólicas". Desse modo, em face do "desamparo subjetivo", só resta ao sujeito se valer das representações fornecidas pela indústria da imagem (Kehl, 2003, p.2).

Para Kehl (2003) trata-se do

(...) desamparo do aperfeiçoamento da alienação: os sujeitos já não se apoiam sobre suas faculdades de julgamento (pensamento), resolução (agir conforme o desejo) e senso moral (suportar a castração). Tampouco sustentam-se sobre os laços que as liga a uma comunidade com base em experiências compartilhadas. Se toda experiência é mediada pelo espetáculo, cuja produção está fora do alcance da experiência mesma, e se o espetáculo "desacostuma as pessoas à subjetividade", elas estão totalmente à mercê dele (Kehl, 2003, p.3)

Essa compreensão da autora dialoga com a compreensão de Bucci (2000), que afirma que o sujeito pós-moderno não está em possibilidade de escolha, pelas vias da mídia, pois a mesma não oferece escolhas. Na verdade, para esse autor, a mídia, materializada enquanto televisão oferece a seguinte opção: "é isso ou nada; é isso ou nada somos" (Bucci, 2000, p.124).

Por esse viés, o sujeito só pode ser o que esse Outro constituído enquanto mídia quer que ele seja. Em outro texto, Kehl (2000) afirma que na significação, a imagem ocupa o lugar do ser (que é, de fato, um lugar vazio); do ponto de vista da constituição subjetiva, se o ser produz uma ilusão de identidade quando o sujeito encontra a sua imagem, o ser se ancora na fortaleza narcísica da imagem do corpo (Kehl, 2000, p.144). 
Nesse sentido, podemos pensar na centralidade do corpo e da imagem corporal para o sujeito pós-moderno. Pela via do consumo, o sujeito se depara constantemente com a imagem de seu corpo, mostrado cotidianamente pela mídia.

Para Kehl (2000) tanto em Lacan quanto em Freud, a constituição da imagem do próprio corpo corresponde à fundação do imaginário. Vejamos:

O imaginário é o que dá consistência à experiência, e é o domínio do corpo. (...). A identificação com a imagem é uma forma de alienação, em que a consistência da experiência subjetiva se ancora na imagem do que se é para o olhar do outro. (Kehl, 2000, p.140)

Isso quer dizer que a mídia funciona como uma instância de dominação e alienação aos sujeitos pósmodernos. Cada vez que somos convidados a responder enquanto consumidores e espectadores (ou telespectadores) perdemos a dimensão de nossas singularidades. A indústria da mídia nos devolve "uma subjetividade reificada, produzida em série, espetacularizada" (Kehl, 2003, p.4). Nesse sentido, o sujeito pós-moderno consome as subjetividades produzidas em série no sentido de criar uma possibilidade de pertencimento social.

Dentro da mídia, escolhemos tratar a publicidade televisiva enquanto o veículo de comunicação de massa mais eficaz e importante ao endereçamento de formas de subjetivação.

Kehl (2000) afirma que no século XX, em várias sociedades industriais e de forma planetária, a televisão produziu e redefiniu novos modos de sociabilidade, causando efeitos sobre a subjetividade. Na verdade, a autora menciona que a televisão é uma instância imaginária, que suspende ou não permite a criação do pensamento. Além disso, ela menciona que o imaginário funciona pela "lógica da realização dos desejos" e por isso, a cada imagem veiculada pela televisão o espectador obtém um pequeno gozo, que cessa o pensamento.

$\mathrm{Na}$ verdade essa autora comenta que o simbólico se funda quando "a imagem já não dá conta do ser". Trata-se do registro da falta. Ao se tratar do Outro, fala-se do campo da linguagem, da possibilidade de inscrição do sujeito na linguagem (Kehl, 2000, pp.140-141).

Entretanto, como já mencionado anteriormente, a pósmoderna cultura, marcada especialmente pelo espetáculo, não permite a falha do imaginário, justamente pela produção incessante de imagens, e por isso compromete a inscrição do sujeito no campo do simbólico. É nesse sentido que o sujeito está predominantemente inscrito no imaginário, destacando-se a própria imagem corporal.
Novaes (2006) menciona que o mundo pós-moderno está em risco de se reduzir à imagem. Se a mídia opera por uma lógica que suspende o pensamento, aprisiona o sujeito "ao fascínio das imagens", ou melhor, a fragmentos de imagens, se considerarmos o trabalho de edição através das quais as diversas mídias operam.

Nesse sentido, encontramos em Roza Junior (2009) uma compreensão sobre a influência desse processo de edição às subjetividades pós-modernas. Para ele, o sujeito pós-moderno tornou-se uma "ilha de edição", uma versão selecionada de características, hábitos, maneiras de se portar e etc., que tem como finalidade suprema mostrar o que "quer que o outro conheça ou aprecie". "Por ilha, entendemos a solidão desse homem frente ao mundo; e por edição, a seleção e combinação de conteúdos escolhidos para serem apreciados pelo outro" (Roza Junior, 2009, p.38).

Assim, tratamos à publicidade enquanto uma das instâncias que mais impulsiona o sujeito a se criar enquanto ilha de edição, principalmente porque a partir dela o sujeito tem condições de eleger seus produtos de consumo, e pode criar uma versão aparentemente singular de si. Além disso, a publicidade devolve-lhe, através de imagens, a possibilidade de se ver no pertencimento à cultura na qual está inserido.

É como se a publicidade lhe dissesse: "Você é parte disso que assiste" ou "Você é único nisso que assiste". Na verdade, ela funciona pela lógica do "um" para "todos": um mesmo modo para todos - com as devidas sutilezas de uma promessa de singularidade. Nesse sentido, ela não se presta a mostrar a própria cultura, mas o universal que habita cada sujeito, mostrando a ilusão de singularidade.

Entretanto, como bem menciona Araújo (2006), a publicidade estrutura modelos a serem reproduzidos pelos consumidores, à medida que adquirem os produtos anunciados. Isso quer dizer que o consumo de produtos está atrelado à subjetividade. Ou melhor, o consumo e o espetáculo criam a ilusão de singularidade a partir do ato de consumo.

De certa forma podemos pensar que a publicidade "democratizou" os processos de subjetivação, pois na medida em que a cultura cria sujeitos impossibilitados de constituir suas próprias subjetividades, possibilita-lhes, pelo menos, a escolha de "comprá-las" e "escolhê-las" dentro das possibilidades ofertadas pelo mercado.

Faz-se necessário apresentar o que a publicidade oferece à subjetividade, ou como convida o sujeito à subjetivação. Vejamos a compreensão de Albuquerque (2004):

A publicidade constrói nossos sonhos de consumo. E é muito interessante o modo como se constroem esses objetos de desejo. É-nos oferecido um produto em uma 
bela embalagem, com carimbo de grife, associado a um estilo de vida e a um lugar na hierarquia social (...). A promessa embutida na publicidade é que, ao adquirir "aquele" produto, você assume imediatamente "aquele" estilo de vida, você se transforma "naquele" personagem. (Albuquerque, 2004, p.96)

Pelas vias da publicidade, parece-nos que a mesma se empenha na criação de imagens que nos fazem crer que a prática mais importante da vida pós-moderna diz respeito ao ato de consumir. Até o próprio ato de consumo se tornou anúncio publicitário, como bem mostra a campanha de uma empresa de cartões de crédito, em que pessoas são mostradas em situação de consumo, e os preços dos produtos são revelados; ao final, mostra-se uma situação de suposta "alegria cotidiana" e se lança o excelente e absurdo slogan: "não tem preço".

Assim, a publicidade se exibe como um convite à formação de uma subjetividade construída na aquisição e na compra. Como menciona Albuquerque (2004, p.100) "Eu sou aquilo que tenho". Ou melhor, "eu sou aquilo que consumo".

$\mathrm{Na}$ verdade, ao consumir, o sujeito pós-moderno busca mais do que simplesmente se tornar um sujeito que compartilha os hábitos e costumes culturais. Vejamos o que Certeau (citado em Novaes, 2006) diz sobre isso:

(...) cooptado pela lógica publicitária e destituído de sua dimensão histórica que lhe conferia densidade e na qual as tradições inerentes à mesma forjavam algum sentido, o sujeito busca nos objetos de consumo sua história, devorando-os, sem que jamais se sinta satisfeito. (Certeau, citado em Novaes, 2006, p.121)

De qualquer forma, a liberdade individual está posta: o sujeito pós-moderno pode consumir o que quiser, quando e como queira: doce ilusão pós-moderna. A publicidade nos oferece o que já desejávamos e ela "dirige-se ao desejo e responde a ele com mercadorias" (Kehl, 2003, p.5).

"Penso, logo existo" é facilmente substituído por "Consumo, logo sou" ou "Sou aquilo que tenho". A subjetividade pós-moderna está definida pelas opções de consumo que o indivíduo, a partir primordialmente da publicidade, percebe como valor a ser reproduzido.

Como menciona Bauman (1998, p.24) “a 'subjetividade' dos consumidores é feita de opções de compra - opções assumidas pelo sujeito e seus potenciais compradores; sua descrição adquire a forma de uma lista de compras". A prática do consumo de determinados produtos, marcas, ou estilos de vida exibidos pela publicidade e pela mídia já constituem o sujeito, que se torna uma reprodução dos sistemas de produção que as compuseram.
A subjetividade se torna comprável, vendível e consumível; a própria vida se torna uma mercadoria. Como diz Barreto (2009, p.198) "toda vivência humana, em essência espontânea e gratuita, flui agora atrelada ao mercantilismo mais imediato". Em outras palavras, é como se qualquer prática do sujeito passasse pelo crivo mercadológico, pelo valor de capital. O tornar-se humano pós-moderno tornou-se também um ato de consumo. Diante dessa realidade proposta pela mídia, há a criação de um sujeito desvitalizado de símbolos, marcado pela falta de pensamento e pela vida em ato, investido em sua própria imagem.

Nesse sentido, se o sujeito transforma-se em imagem, ou melhor, se sua faceta subjetiva mais importante se torna a imagem de si, não soa estranho que ele ambicione reconhecimento social e visibilidade através da apreciação do outro acerca de sua imagem. De qualquer modo, colocado o sujeito do espetáculo, ele se faz existir quando se torna visto. "Sou visto, logo existo". Se não sou visto, não existo?

\section{Ser Mulher}

Ao nascer, o ser humano é designado "homem" ou "mulher", de acordo com a formação de seus órgãos sexuais. Assim, a primeira distinção humana acontece em relação à anatomia: sexo feminino ou sexo masculino, ou melhor, de acordo com as características sexuais anatômicas primárias. Desse modo, a distinção anatômica e biológica, presente da natureza, é a primeira marca da posição do sujeito na cultura.

Pondé e Tiburi (2009) mencionam que há diferenças entre homens e mulheres que são biológicas, e há diferenças que são culturais. Kehl (1998, p.27) fala da diferenciação sexual na cultura como um processo a ser produzido por cada sujeito na cultura, a qual possui uma trama simbólica de significações de pertença a um ou outro grupo identitário, que "designa lugares, posições, deveres, traços identificatórios".

Assim, para além das diferenças anatômicas estão as diferenças entre homens e mulheres. Em qualquer cultura de qualquer tempo essas diferenças existem. Na verdade, constatar isso é fundamental para começar a compreender a condição da mulher pós-moderna.

As mulheres foram, durante séculos, concebidas dentro do referencial masculino. Na bíblia, em Gênesis, a narração sobre o mito da criação elucida a condição da mulher. O homem foi criado à imagem e semelhança de Deus. De acordo com a Biblia Sagrada a criação da mulher possui outra trama: "E disse o Senhor Deus: não é bom que o homem esteja só; far-lhe-ei uma adjutora que esteja como diante dele" (Gn 2:18). Além disso, no mito da criação Eva 
foi criada por Deus a partir de uma das costelas de Adão. Isso quer dizer que a existência dela está ligada, na bíblia, à criação dele. Entretanto a existência dele independe da dela.

Essa é uma constatação importante da diferença cultural entre homens e mulheres, que circunscreve o lugar ocupado pelas mulheres na cultura ocidental. Na verdade, elas foram colocadas, desde o início do cristianismo, no lugar de "servidão" aos homens.

Até meados do século XVIII os sexos eram concebidos através do paradigma do sexo único. O sexo masculino era tratado como perfeito, e o feminino, como imperfeito. A partir desse século, com o advento dos ideais da Revolução Francesa, houve a constituição de um discurso sobre a diferença sexual entre homens e mulheres. Entretanto, manteve-se a hierarquização entre os sexos, que por uma perspectiva predominantemente biológica, considerava o sexo masculino em sua superioridade, e o feminino, em sua inferioridade (Birman, 2001).

Pelo nosso recorte teórico entendemos que a compreensão do processo de tornar-se mulher começa no século XIX, época em que houve uma profusão de discursos científicos no sentido de criar uma proposta de identidade biologicamente feminina, a definir e delinear finalidades e inserções sociais aos sexos feminino e masculino, para a criação e manutenção da ordem da família burguesa.

Para Birman (2001):

Ser homem ou mulher, então, seria a consequência inevitável ou insofismável de traços inscritos na estrutura do organismo. Esses traços seriam indeléveis, na medida em que seriam produzidos pela natureza biológica. Consequentemente, passou a existir um abismo intransponível entre os sexos, já que uma essência particular e perene os diferenciava (...). (Birman, 2001, p. 43)

Assim, através da medicina social, da higiene e da saúde pública essa nova modalidade de discurso se exerceu de forma legítima sobre os corpos, principalmente sobre os das crianças e das mulheres. Mas o que realmente estava em questão era a manutenção da mulher na posição de maternidade, já que uma das preocupações da época era a formação de capital humano para futuras acumulações de riquezas (Birman, 2001).

As diferenças sexuais foram pensadas e tratadas de acordo com os âmbitos biológicos, designando papéis, funções e posições a homens e mulheres. Birman (2001) menciona que a figura da mulher era marcada pela presença do corpo somático, dos impulsos e dos afetos. E a figura do homem, marcada pela civilização e pela dominância do entendimento.
Nesse momento do século XIX houve a incursão da Psicanálise no mundo ocidental. Na verdade, ela começou a ser criada por Freud a partir de sua escuta e de seu olhar sobre as mulheres histéricas, que podem ser consideradas as primeiras feministas, já que reivindicavam, em estado de conversão, as demandas em relação ao corpo, ao desejo e ao erotismo.

A partir disso podemos pensar que a mulher se fez sujeito, pela Psicanálise, ao se fazer ser escutada e vista pelo outro, ou melhor, à medida que seu corpo erógeno pôde ter visibilidade e seu desejo sexual pode ser reconhecido (Fortes, 1998). Dessa forma, nos arriscamos a dizer que a mulher, precisa ser olhada (e escutada) para se tornar sujeito.

Na verdade, a histeria é compreendida como uma rebeldia à condição da mulher do século XIX (Birman, 2001; Fortes, 1998). Esses dois autores mencionam que apesar dos esforços de Freud na escuta e compreensão das mulheres desse século, as mesmas permaneceram enquanto seu grande enigma.

Tanto é que Birman (1999) comenta que o grande enigma na obra de Freud revelou-se nas questões em relação à sexualidade feminina e à feminilidade, o que Freud denominou como continente negro da mulher.

Em outro texto, Birman (2001) comenta que o ser da mulher, na obra freudiana é marcado pelo velamento e pela obscuridade, em face da evidência do órgão anatômico masculino. Nesse sentido, as mulheres freudianas seriam marcadas pelo enigma da feminilidade, que é da "ordem do quase indizível" (Birman, 2001, p.182).

Fortes (1998) comenta sobre a condição das mulheres do século XIX:

Presa ao universo da maternidade, participando de uma dialética de servidão ao homem para evitar sua angústia de morte, obrigada a recalcar a sua sexualidade, impossibilitada de trabalhar e inserir-se no espaço público, a mulher freudiana testemunha uma espécie de melancolia da mulher. Sair desta melancolia é apostar em uma saída sublimatória para a mulher, na possibilidade da criação de novos objetos na cultura, objetos estes que possam vir a ser fonte de satisfação, ao serem pensados dentro do campo da alteridade, isto é, a partir da circulação pulsional dos laços sociais. Tal façanha certamente exige suportar um certo desamparo e uma boa dose de dor. (Fortes, 1998, p.303)

Birman (2001) considera que o discurso freudiano acerca da subjetividade da mulher e da condição feminina é um discurso forjado, concernente à realidade da mulher do século XIX, em que os discursos se pautavam por uma hierarquia, que estaria inscrita na ordem da natureza, pela 
modalidade de posse ou não posse do operativo falo. Além disso, esse autor comenta que na obra de Freud, a condição masculina é tratada como o "paradigma universal do ser humano" (Birman, 2001, p. 196).

Pela psicanálise, a constituição de homens e mulheres enquanto sujeitos, acontece mais ou menos da mesma maneira até que se instaure o processo denominado como Complexo de Édipo, que acontece na fase fálica. Além do Édipo, essa fase é marcada pela castração, e pela diferenciação sexual (presença ou ausência de pênis).

Freud (1905/1996a) discorre sobre as fases do desenvolvimento da sexualidade infantil que antecedem a instauração do Complexo de Édipo, que correspondem às fases oral e anal. Posterior a essas duas fases, instaura-se a denominada fase fálica, marcada pelo operador central: falo que pode ser compreendido como o significante primordial da diferença sexual, ou ainda como o símbolo cultural de poder. $\mathrm{Na}$ infância, o falo está representado pelo pênis (Sodré, 2003).

Kehl (1998, pp. 416-417) afirma que a "condição humana" é mais ou menos a mesma para homens e mulheres: "somos todos castrados". Com a instauração da fase fálica, o destino separa homens e mulheres, criando duas modalidades de falo ou de castração em que meninos e meninas inventam e aprendem diferentes malabarismos "na passagem tortuosa e apertada do Édipo".

Essa noção de "condição humana", que denota a castração a homens e mulheres, vem ao encontro da formulação do desejo, concebida por Birman (2001). Vejamos:

O desejo, aqui, é concebido como aquilo que busca preencher uma falta e que implicaria, de algum modo, a evocação da experiência de castração. $O$ círculo se fecha então na preeminência atribuída ao falo na experiência psíquica, seja esta do sujeito feminino ou masculino. O falo seria, enfim, pregnante e absoluto no funcionamento desejante do sujeito. (Birman, 2001, p. 207)

A partir da fase fálica, o destino começa a operar no sentido de designar posições distintas a homens e mulheres. Os dois modos operativos de falo constituem homens e mulheres, de forma diferente, e se referem à angústia de castração, nos meninos; e a inveja do pênis, nas meninas.

Freud menciona a diferenciação entre o processo vivido por meninos e meninas, na fase fálica, da seguinte forma: "Enquanto, nos meninos, o complexo de Édipo é destruído pelo complexo de castração, nas meninas ele se faz possível e é introduzido através do complexo de castração" (Freud, 1925/1996b, p. 285).

A castração feminina acontece pela via da realização, a masculina, pela via da ameaça. Para Freud (1933/1996d) o complexo de castração, tanto em meninos quanto em meninas, acontece quando da percepção da diferenciação sexual (constatação dos órgãos genitais do sexo oposto). Basicamente, a diferença do processo em meninos e meninas acontece porque para os meninos, a castração se faz sob o "temor da castração": ameaça de ficar sem o órgão genital, concebido como um órgão à parte do corpo. Já para as meninas, o processo acontece sob a forma de aceitação da castração e posterior "inveja do pênis": constatação de que os meninos possuem "algo a mais", que elas desejam tomar para si.

Nesse sentido, a entrada das meninas na fase fálica, terceira fase do desenvolvimento libinal, corresponde ao momento da descoberta da diferenciação sexual: quando percebem, no sexo oposto, o pênis: "algo a mais", que lhes falta e que desejam ter. Para Freud (1925/1996b, p.282) o processo de dar-se conta da condição de castrada acontece quando a menina "ultrapassou sua primeira tentativa de explicar sua falta de pênis como uma punição pessoal para si mesma, e compreendeu que esse caráter sexual é universal".

Freud (1931/1996c, 1933/1996d) retoma os destinos possíveis à menina, depois que ela se reconhece em sua condição de castração, que pode acontecer pela via da inibição sexual ou neurose, do complexo de masculinidade, ou da feminilidade normal. Na primeira, ao reconhecer a inferioridade do sexo feminino, vive uma "revulsão à sexualidade", ou seja, abandona a realização da sexualidade; na segunda vive a "auto-afirmatividade", na fantasia de conseguir um pênis (prenúncio de escolha por objeto homossexual); e na terceira alcança a "feminilidade normal", quando a figura do pai é colocada na posição de investimento libidinal, o que proporciona à resolução do complexo de Édipo (Freud 1931/1996c, pp.237-238).

Compreende-se assim que a menina inicia o desenvolvimento de sua feminilidade a partir da constatação do sexo oposto, da diferenciação sexual, e da inveja do pênis. Aceitar ou não aceitar a castração é uma condição importante que dará, futuramente à mulher, a possibilidade de escolher o destino de sua sexualidade. Ao aceitá-la inicia o processo de construção de sua feminilidade.

É fato que a sexualidade feminina foi tratada pela Psicanálise, nas primeiras obras de Freud, como "análoga à do homem". Isso corresponde a dizer que embora a sexualidade feminina tenha sido referenciada na sexualidade masculina, já se constatava que a mesma era marcada por suas particularidades.

Entretanto, para Birman (2001, p. 178) “(...) o que o discurso freudiano realizou foi sempre a narrativa masculina do complexo de Édipo, sendo a narrativa feminina deixada inicialmente de lado". Para esse autor, o ser da mulher é 
elucidado por Freud, por comparação ou subtração a partir da condição masculina.

De qualquer modo, a construção da feminilidade, nas meninas, inicia-se a partir do Complexo de Édipo, na trama com a castração e a diferenciação sexual. Vejamos:

Com a transferência, para o pai, do desejo de um pênisbebê, a menina inicia a situação do complexo de Édipo (...). Num menino, o complexo de Édipo, no qual ele deseja a mãe e gostaria de eliminar seu pai, por ser este um rival, evolui naturalmente da fase de sexualidade fálica. A ameaça de castração, porém, impele-o a abandonar essa atitude. (...). O que acontece à menina é quase o oposto. O complexo de castração prepara para a ligação com sua mãe através da influência de sua inveja do pênis, e entra na situação edipiana como se esta fora um refúgio. $\mathrm{Na}$ ausência do temor de castração, falta o motivo que leva o menino a superar o complexo de Édipo. As meninas permanecem nele por um tempo indeterminado; destroemno tardiamente e, ainda assim, de modo incompleto. (Freud, 1933/1996d, p.129)

No processo vivido por meninos e meninas durante o complexo de Édipo a mãe configura-se enquanto “objeto original" (Freud, 1925/1996b, p.280). A mãe é a primeira sedutora da criança, seja menina ou menino, já que os primeiros cuidados corporais são realizados predominantemente pela figura materna. Entretanto, as meninas realizam um processo a mais, já que o pai se torna posteriormente seu objeto de investimento libidinal. Ela se afasta da mãe, no período edipiano, quando a responsabiliza por "não ter-lhe dado um pênis apropriado", ou seja, por sua condição de castração (Freud, 1931/1996c, pp. 241-242).

Freud (1933/1996d, p.128) afirma que o "brincar de bonecas" da fase fálica antecede "o desejo do bebê", mas não é ainda, de fato, feminilidade, é mais identificação com a mãe. No desenvolvimento normal da feminilidade, quando a menina vincula-se ao pai, na verdade, seu desejo é o de "possuir o pênis que a mãe lhe recusou". Entretanto, ele afirma que o estabelecimento da situação feminina só se efetiva quando "o desejo do pênis for substituído pelo desejo do bebê”, numa equivalência simbólica.

Isso leva a pensar na seguinte equação: a mulher abandona o desejo do pênis e se torna mulher, pela via da maternidade, já que substitui o desejo do pênis pelo desejo do filho. Para Birman (2001) a manutenção da mulher na posição de maternidade como destino possível à feminilidade corresponde, no discurso freudiano, à marca do patriarcado. Desse modo, a maternidade se circunscreve, para a mulher, enquanto possibilidade de inserção no campo social (Birman, 2001, p.55).

Sobre a inveja do pênis, Freud (1925/1996b, p.283) considera que se trata do processo responsável por criar um desinvestimento da menina no objeto materno, já que nesse momento, a mãe é considerada a responsável pela falta do pênis. Assim, há um posterior investimento na figura do pai, suposto detentor do falo.

Freud (1931/1996c,1933/1996d) postula que o desenvolvimento sexual feminino, para atingir a feminilidade, precisa passar de uma posição masculina para uma posição feminina. $\mathrm{Na}$ fase fálica, fase de reconhecimento da diferenciação sexual, as meninas tomam uma posição feminina quando trocam de zona erógena e de objeto. Entretanto, em meninos e meninas, a fase é inicialmente masculina. Ele afirma que o caminho para o desenvolvimento da feminilidade, nas meninas, se abre quando da troca do objeto materno para o objeto paterno (Freud, 1931/1996c).

Após essa troca, a menina inicia um processo de competição com a mãe, pelo amor do pai. Entretanto, para se sair bem dessa situação edípica, precisa renunciar ao amor paterno, identificar-se com a figura materna e como menciona Kehl (1998, p.417), posteriormente apostar na conquista do amor de outros homens, a partir de sua condição de castrada, o que lhe parece improvável, pois ela duvida que o detentor do falo se interessará por alguém que "ostenta uma falta tão evidente".

Nesse sentido, Birman (2001, p.180) menciona que a constatação da castração, na mulher, a conduz na busca do órgão faltante. Desse modo, a mulher estaria sempre em condição de buscar o que lhe falta. Podemos pensar, a partir disso, que a feminilidade, trata-se, na verdade, de haver-se com a falta.

Ao identificar-se com a mãe, sua antiga rival, ela aprende algumas artimanhas com uma "tão castrada quanto ela" (Kehl, 1998, p. 419). Nesse sentido, a autora menciona que a menina se dá conta de que o pai fálico não se deixaria seduzir por "um ser incompleto", e que por isso a mãe o engana com os truques da feminilidade: "penteado, enfeites, batom, tecidos, perfume". Nesse sentido, podemos pensar que a menina aprende a disfarçar e esconder sua falta ou incompletude através dos processos de embelezamento corporal. A autora ainda menciona que a feminilidade se torna um jogo de esconde-esconde, com a "estranha função de esconder justamente o que não está lá".

Para Novaes (2006), a partir da sedução, pelas artimanhas da beleza, a menina (ou a mulher) busca mais do que uma compensação fálica, busca o olhar desejante do outro. Vejamos:

O que a menina busca encontrar no campo do masculino não é propriamente o que lhe falta, mas o reconhecimento do que foi posto em seu lugar: um olhar amoroso sobre tudo que em si é visível. É, portanto, na busca desse olhar 
que encontraremos o sujeito feminino. (Novaes, 2006, p.238)

Novaes (2006) continua: "Ora, se 'beleza e atração são idênticos' e o sujeito feminino é aquele que se define por exercer a atração, então ser bela é uma condição e uma imposição para tal posição subjetiva" (p.240).

Nesse sentido, Birman (2001, pp.20-21) comenta que a beleza e a sedução se inscreveriam ao corpo da mulher como uma contrapartida à inveja do pênis, considerada o motor crucial de funcionamento psíquico feminino, ou como uma espécie de compensação, já que marcada pela "inferioridade genital por ser despossuída da magnificência do pênis/falo". Para esse autor, a beleza e a sedução feminina seria uma tentativa da mulher de inscrever o falo na totalidade do corpo.

De qualquer forma, Birman (2001) constata que, pelo discurso freudiano, a solução para o horror da experiência de castração, própria às mulheres, seria sempre a "plenitude fálica, por intermédio de algum objeto” (p.206).

Entretanto, Freud deixa entrever, ao final de sua obra, que a feminilidade poderia ser tratada de uma outra forma. Birman (1999, 2001) e Kehl (1998) em seus estudos tratam à feminilidade como outra forma de registro psíquico. $\mathrm{Na}$ verdade, esses autores tratam-na não como uma oposição à noção de masculinidade, mas sim como a origem do psiquismo, anterior à ordem fálica. Nesse sentido, a feminilidade é tratada como um território de ausência e falta.

Para eles, o falocentrismo, marcado pela organização e ordem e a feminilidade, marcada pela desorganização e desordem são entendidos como formas opostas de registro psíquico. E compreendem que a feminilidade antecede a instauração fálica. Assim, revelam que a instauração fálica relega a feminilidade à condição de "continente negro". É nesse sentido que Birman (2001, p. 226) menciona que a ordem fálica silencia a feminilidade.

Desse modo, tanto homens quanto mulheres têm sua subjetividade formada por esses dois registros psíquicos: feminilidade e ordem fálica. Não se trata de substituir um registro por outro, mas antes de se haver com essas duas condições, próprias ao ser humano. Sobre isso Kehl (2003, pp.2-3) comenta que a feminilidade não se trata de uma condição que se suporta estar o tempo todo, por sua proximidade à angústia, à morte, ao horror. Ao contrário, ela menciona a necessidade de se manejar o falo e a castração, para poder manejar os acessos à feminilidade.

\section{Ser Beleza}

O homem sempre desejou imortalizar a beleza, colocála na condição de permanência. Em se tratando das pósmodernas práticas e técnicas de aperfeiçoamento corporal, isso se torna possível. A imortalidade da beleza não, mas a ampliação de sua permanência.

O fundamento de beleza, sobretudo às mulheres, é um acontecimento histórico; produto da realidade, ou melhor, produto da relação do corpo em determinada cultura, e em determinado tempo. Entretanto, na pós-modernidade os cuidados com o corpo são tratados como "o caminho legítimo e seguro para a felicidade individual" (Novaes, 2006, p.84).

Para Carreteiro (2005) o corpo se tornou um "objeto de investimento privilegiado". A autora trata da expressão da corporeidade enquanto "excesso" e enquanto "beleza". O corpo do excesso é comandado pela urgência permanente e pela "imediaticidade" e marcado pela compulsão: "sucessão de atos na busca contínua de um possível gozo" (Carreteiro, 2005, p.70). A excessiva busca por um corpo desejável, com ideais de beleza, técnicas de remodelagem, práticas esportivas e cirurgias faz parte do corpo como excesso, mas também está presente no corpo-beleza, marcado essencialmente pela estética.

Tudo isso diz de um valor muito presente nas sociedades ocidentais: o culto à aparência. Denunciase, assim, uma relação com a exterioridade da forma e a promoção de modelos de identificação corporal externos ao sujeito (Novaes, 2006).

Herrmann (2004, p.3) afirma que na pós-modernidade o homem está "posto diante de seu corpo". Além disso, o autor menciona que esse é o período histórico em que o homem vive mais intensamente uma relação problemática com seu corpo, a qual ele nomeia como artificial, já que o corpo se tornou uma "massa de modelagem".

$\mathrm{Na}$ estética do século XX "cava-se um espaço psicológico em que o indivíduo das sociedades democráticas sonha com inumeráveis transformações: submeter o conjunto da aparência, em especial, ao único exercício da vontade" (Vigarello, 2006, p.163).

Le Breton (2006, p.78), falando sobre Michèlle Pagès-Delon (1989), comenta que as aparências corporais tornaram-se uma forma de capital. Há verdadeiros investimentos pessoais no corpo, ou melhor, na aparência do corpo: as cirurgias plásticas, as práticas esportivas, os tratamentos estéticos, o consumo de produtos cosméticos e de roupas, a dietética, etc. Através das aparências, o homem pós-moderno se apresenta "como se fosse um cartão de visitas vivo", e se coloca "sob o olhar apreciativo do outro". Na cultura brasileira, há essa forte associação entre corpo e prestígio social, principalmente entre as mulheres dos 
estratos sociais médios.

Considerando que a mulher do século XXI é ainda e também a mulher do século XX, e que tem memórias e indagações do século XIX, vamos retomar um pouco a beleza da mulher e de seu corpo nesses períodos.

No século XIX surge a ideia de um corpo que visa ao aperfeiçoamento graças ao progresso da ciência (morfologia, genética, psiquiatria, psicanálise) e na mesma vertente, estética, educação física, cosmetologia, dietética e cirurgia (Novaes, 2006). Além disso, o discurso higienista inaugurou a possibilidade da mulher de ser bela. Parece que essa possibilidade tornou-se, nas últimas décadas do século XX e nesse início de século XXI, uma realidade buscada e investida.

Para Novaes (2006) a beleza começou a ser construída a partir de padrões pré-definidos, e deixou de ser um privilégio genético e natural de alguns para se tornar uma necessidade de muitos. O mercado de beleza começa a oferecer inúmeras opções de como se tornar uma mulher mais bela: a cosmética e os produtos de higiene pessoal, os procedimentos dermatológicos e estéticos, a moda, a dietética, as atividades físicas de modelação do corpo, e os procedimentos médicos: cirurgias plásticas, cirurgias bariátricas (redução do estômago), lipoaspirações (remoção da gordura corporal) e lipoesculturas (remoção da gordura corporal e redefinição das formas corporais). A autora usa o termo "corpolatria", de Courtine (1995), para dizer que o homem pós-moderno trata à estética nos mínimos detalhes da massa corporal. E menciona que vivemos sob a égide do "olhar minucioso sobre a aparência", e que a partir do capitalismo a beleza passou a ser comprada (Novaes, 2006, p. 71).

Na década de 20 do século XX houve um forte crescimento das indústrias de cosméticos, que estavam voltadas principalmente à aparência das mulheres. Aumentaram-se os cuidados com o corpo e a beleza passou a ser definida pelos padrões do cinema de Hollywood, das revistas, da moda e da publicidade e se tornou um dos fatores constituintes da identidade da mulher moderna (Mira, 2003).

Apesar de já engendradas as técnicas de aperfeiçoamento corporal, considera-se que até a primeira metade do século $\mathrm{XX}$ a manipulação e o embelezamento do próprio corpo eram práticas moralmente condenáveis, principalmente pela fé católica, já que o poder de transformação caberia somente a Deus. "Se o homem foi feito à Sua imagem e semelhança, não se pode interferir na criação divina" (Novaes, 2006, p.165). Entretanto, para essa autora, na pósmodernidade o cirurgião plástico ocupou o lugar de criador: transformador de velhas, em novas formas.

Vigarello (2006) menciona que na década de 1920, os cortes de cabelo feminino se tornaram mais curtos, trocando o "pesado e embaraçador pela fluidez e leveza" (Vigarello, 2006, p.145). Esse corte representa para o autor o desnudamento da força misteriosa, dos segredos e esconderijos femininos. Além disso, ele menciona que a tecnologia da beleza equivale a afirmações individuais, e coloca o corpo em condição de "nova liberdade", em resposta ás expectativas sociais.

Através dessa "nova liberdade", ao longo do século $\mathrm{XX}$, a beleza tornou-se um produto vendido em vários segmentos de mercado, e assim, uma mercadoria mais acessível. Houve uma democratização de beleza, ou uma artificialização do corpo natural. Nesse sentido a beleza do corpo se torna um signo cultural.

Até os anos 1930 a preocupação estética das mulheres era com o rosto e a prática de embelezamento mais comum era a maquiagem. A partir desse período as preocupações começaram a ser com o refinamento da silhueta. Surgem preocupações com a forma física, os pesos e as medidas, que se inscrevem enquanto práticas estéticas com intuitos de melhorar a saúde (Vigarello, 2006).

Novaes (2006, p. 55) menciona que a criação do espelho favoreceu a uma nova relação do ser humano com sua imagem corporal. Ela também afirma que um dos grandes movimentos que o homem faz em relação ao corpo é tentar aproximar-se de sua imagem. Desse modo, a pósmodernidade é marcada pela busca incessante da criação fidedigna de uma imagem corporal.

Essa autora também afirma que a estética pós-moderna pressupõe "ser jovem, magro e saudável". O corpo parece ter se tornado o locus dos ideais da beleza. Além disso, ela trata a beleza como o grande produto de consumo oferecido às mulheres pós-modernas. Esse investimento se torna uma prática de "controle do próprio corpo", ou um "investimento em autoestima" ou ainda um "agenciamento de si". Podemos pensar que o investimento e o controle da aparência são um produto do século XX. A partir disso pergunta-se: de que outra forma a mulher controla o próprio corpo?

O ideal de beleza, proposto às mulheres pós-modernas trata-se da expressão do corpo-beleza (Carreteiro, 2005), o qual representa o fascínio da pós-modernidade pela estética e pela perfeição. Esse corpo tornou-se o mais valorizado e idealizado para e pelas mulheres. Não é por acaso que existe todo um mercado designado para a beleza estética do corpo feminino, com a finalidade de favorecer a mulher ao alcance dos ideais de beleza. Desse modo, a questão da aparência e da corporeidade enquanto expressões de beleza estão intimamente relacionados à mulher e a seu corpo.

"A imagem da mulher na cultura confunde-se com a da beleza. Este é um dos pontos mais enfatizados no discurso 
sobre a mulher: ela pode ser bonita, deve ser bonita, do contrário não será totalmente mulher" (Novaes, 2006, p.85). Essa autora utiliza o termo de Baudrillard: "moralização do corpo feminino" para dizer que a beleza se tornou uma questão de ética.

A expressão da corporeidade ou da aparência física relacionada à mulher pós-moderna parece estar relacionada à tríade "beleza-magreza-jovialidade" (Goldenberg, 2005). Isso leva a pensar que essa corporeidade é o ideal de corpo proposto pelas propagandas de produtos cosméticos e de higiene pessoal. Ou melhor, esse ideal se faz presente de forma assustadora, nesses segmentos de mercado.

Sobre isso, vejamos o posicionamento de Novaes (2006):

O que é normativo para a mulher contemporânea não é o fato de os modelos de beleza serem impostos, uma vez que o discurso sempre foi esse, nem mesmo de que seja dito que ela deve ser bela, mas o fato de se afirmar, sem cessar, que ela pode ser bela, se assim o quiser. (Novaes, 2006, p.90)

Tem-se a impressão de que à medida que as conquistas femininas efetivaram-se novas formas de existência foram construídas, principalmente em relação à estética, que passou a ser supervalorizada. O slogan de uma revista feminina brasileira é "Nova, cada vez mais nova", e o nome de uma empresa de cosméticos é "Avon" - a palavra nova de trás para frente. Não é por acaso que encontramos no trecho da música "Diariamente", de Nando Reis, a sugestão da aparência física à mulher: "Para parecer mais nova Avon".

A luta da mulher pós-moderna passou a ser contra as rugas, a idade, o tempo, e a gordura; e a grande conquista almejada é o corpo perfeito. Além disso, Novaes (2006) cita a frase de Edmonds (2000), que revela essa faceta da condição das mulheres na cultura brasileira: "No Brasil, as mulheres não envelhecem, elas ficam todas loiras".

No Brasil, há um grande investimento, pela mulher, em beleza. Goldenberg (2005) utiliza dados da Sociedade Brasileira de Cirurgia Plástica, referentes ao ano de 2003, para dizer que $70 \%$ das cirurgias plásticas foram realizadas em mulheres, principalmente para esculpir um corpo perfeito. Além disso, há uma necessidade por parte das mulheres de imitar, ou de se apropriar dos padrões corporais de beleza socialmente valorizados, e divulgados pelas grandes mídias.

O corpo feminino e a beleza tornaram-se socialmente valorizados como capital cultural. Nesse sentido, Novaes (2006, p.83) comenta que a beleza se tornou moeda de troca para as mulheres. Goldenberg (2005, p. 66), cita Bourdieu (1990), para dizer que as mulheres ganharam um "nome", transformaram-se em "capital físico" "a partir de seu corpo, sua aparência, sua beleza".

Vigarello (2006, p.157) fala que o cinema revolucionou o mundo das aparências, ao criar diversos ícones de beleza, verdadeiras "estrelas", cujos padrões de beleza se tornaram almejados pelos telespectadores. Ele também menciona que a associação da imagem e do nome de determinadas atrizes em anúncios promoveu uma democratização da "vontade de embelezamento", que a partir do sistema industrial e do mercado de consumo, tornou o acesso à beleza uma realidade a milhares de mulheres.

Na verdade, esse autor menciona que a criação dessas imagens estelares coloca essas mulheres, aos olhos de quem assiste, na condição de inacessibilidade, como imagens, estátuas ou esfinges construídas com a finalidade de serem olhadas e admiradas (Vigarello, 2006, p.161). Desse modo, podemos pensar na instauração de uma beleza construída para ser olhada.

Para Novaes (2006) o corpo feminino, expressão da feminilidade relacionada à beleza, à saúde, e à magreza responde ao desejo do outro. Melhor dizendo, o investimento em beleza vincula-se à visibilidade social. Ela percebe nas falas de suas entrevistadas a "busca de aprovação do outro", e a noção de que o corpo ideal é aquele que possibilita a sedução, ou seja, um corpo que seduza os homens. Uma de suas entrevistas afirmou: "Me alimento muito mais dos elogios que recebo" (Novaes, 2006, p.133).

Essa autora nos convida a pensar que a constituição humana acontece pela via da alteridade, a partir do olhar do outro. Por esse viés, a lógica da constituição do sujeito mulher, em sua dialética entre o espelho e o olhar do outro se torna determinante na estruturação psíquica da mulher.

Para ela, a beleza pressupõe o olhar do outro. Ela chega a dizer de uma invasão do olhar do outro sobre o corpo, que se faz sentida principalmente se considerarmos o espetáculo como forma de estabelecimento dos laços sociais. Entretanto, ela vai de um extremo a outro para pensar no projeto de beleza do corpo feminino. Por um lado, a autora considera a escravização do corpo feminino a padrões de beleza inatingíveis. Por outro, considera a possibilidade da mulher de "intervir na construção da própria imagem" (Novaes, 2006, p.20).

Ela menciona a artista e bodybuilder ${ }^{2}$ Orlan, que já realizou dezenas de intervenções corporais, inclusive cirúrgicas. Para a autora, ela pode ter alcançado o sonho de milhares de mulheres: "a autonomia e a diferenciação do próprio corpo/ser" (Novaes, 2006, p.89).

Dependendo do olhar à artista, ela alcançou ou não a liberdade conquistada. Por isso pergunta-se: Orlan é $2 \quad$ O termo "bodybuilding" significa a construção da corporeidade sem a preocupação com a força e com a saúde. 
um corpo liberto numa mulher aprisionada, ou um corpo aprisionado pelos ideais de perfeição corporal, através de dezenas de intervenções cirúrgicas, numa mulher liberta?

Será essa a independência e a liberdade conferidas à mulher: a posse sobre os destinos do próprio corpo? $\mathrm{O}$ direito de remodelar para se enquadrar ou se diferenciar? Essa liberdade parece mais um remoto controle. Seja como for, o processo de embelezamento tornou-se uma ordem cultural ás mulheres.

Assim, a beleza tornou-se um projeto individual e o fracasso paira sobre a mulher não investida em beleza. Nesse sentido, ser bela se torna a maior expressão de singularidade da mulher. Vejamos:

A aparência passa então a ser o que de mais particular, único e singular o indivíduo possui. Paradoxalmente, o que há de mais íntimo, pessoal e com maior atribuição de valor social está na superfície do sujeito - na pele. (...) então aí reside uma contradição, no sentido de que a busca é coletiva, e não pessoal, assim como nada tem de particular e específica; ao contrário, perde-se em um padrão. (Novaes, 2006, pp.57-58)

$\mathrm{Na}$ cultura brasileira a ordem de beleza se dirige menos aos homens. Melhor dizendo, os desleixos com o corpo são mais toleráveis em relação aos homens, muito mais do que às mulheres. Além disso, o não investimento da mulher em beleza é considerado um desvio moral, ou falta de vaidade. (Novaes, 2006, p.70).

A beleza feminina é olhada em seus mínimos detalhes: unhas feitas, maquiagem, depilação, uso de roupas da moda, e etc. Em nosso entender, qualquer deslize na aparência feminina é como um pequeno arranhão feito à construção de sua imagem de perfeição. Assim, podemos entender a estética corporal enquanto um olhar minucioso sobre a mulher, em que a atenção aos detalhes de cada parte do corpo é amplamente realizada. A imagem corporal mostrada cotidianamente à mulher corresponde a uma impossibilidade de alcance na realidade. Desse modo, a imagem se transforma em potência, e a realidade vivida no corpo se torna uma frustração.

Percebe-se que a cultura brasileira não concedeu à mulher o relaxamento ou o desleixo em relação aos cuidados estéticos com o corpo. Mesmo com o tempo reduzido pelo advento no mundo do trabalho, para ela não há a desculpa da falta de tempo para a beleza até porque os eletrodomésticos se prestaram a acelerar as tarefas domésticas designadas a ela e a assegurar que o trabalho no mundo privado não custasse privações ao lar, aos filhos, e ao marido.

Novaes (2006) afirma que os qualitativos estéticos estão associados, na mulher à feminilidade, embora os ideais pós- modernos de feminilidade exijam a beleza autêntica (p.166). Entretanto, já dissemos que a beleza, na pós-modernidade, tornou-se um artigo de consumo. Por esse ponto de vista tratamos o aperfeiçoamento estético através da cosmética enquanto a mais autêntica "farsa" cultural, engendrada à mulher.

\section{Ser Intervalo}

No início do século XIX as mulheres começaram a ler os folhetins, que são "a fusão histórica do romance burguês com o melodrama popular", e que surgiram como uma imprensa de massa destinada a elas. Assim como os romances e folhetins, a telenovela, a rádio novela e a fotonovela foram produzidas, essencialmente, para o público feminino, com a seguinte fórmula "lágrimas, mulheres e empresas que vendem sabão" (Mira, 2003, p.26). Desse modo, as mídias tornaram-se parte da constituição da mulher ocidental e persistem até hoje, no que diz respeito ao romantismo e à ficção presentes, nas revistas, na televisão, e na publicidade.

Ao longo do século XX a nova forma de concepção da mulher passou a valorizar a estética do corpo e a independência financeira da mulher, o que contribuiu para a construção de uma nova subjetividade feminina. Temse a impressão de que tal valorização foi tão reforçada pelos meios de comunicação que ocorreu uma banalização do corpo feminino, pois a mídia o colocou em constante condição de exposição através de diversos meios, o que, de certa forma, contribuiu para a criação de padrões corporais femininos.

A beleza mostrada pelas criações midiáticas gera artifícios à imagem, que leva o telespectador a vê-la por outro aspecto: sobrenatural e metamorfoseada em aparência de superioridade, encantamento e fantasia (Vigarello, 2006).

Num comercial televisivo de uma marca de cosméticos que deu início a uma campanha em prol da "real beleza" é mostrada uma jovem mulher, com o foco da câmera em seu rosto. Ela é mostrada em cinco momentos distintos: natural (sem maquiagem), maquiada e penteada, fotografada, a imagem corrigida em photoshop (programa de edição de imagens) e por fim, a imagem impressa em outdoor. O comercial inteiro trata de uma metamorfose que se concretiza: a transformação de uma mulher comum em uma linda imagem publicitária.

O comercial revela o processo de embelezamento pelo qual uma modelo passa até que sua imagem seja veiculada pela mídia. Denuncia-se, assim, que as imagens publicitárias mostradas pelas diversas mídias são editadas: há um processo de aperfeiçoamento da imagem. Há a escolha dos melhores ângulos, da luminosidade ideal, proximidade ou afastamento da câmera. 
A imagem final realmente parece perfeita, se comparada à naturalidade da realidade. Entretanto, a imagem e a beleza construídas pela publicidade não existem na realidade vivida. Na verdade, o que existe é a busca da mulher pósmoderna para se transformar, em sua realidade, nessa imagem assistida.

Desse modo, a tríade beleza-magreza-jovialidade, na pós-modernidade, tornou-se uma obsessão feminina, e um estilo de vida. Parece que apenas o corpo feminino que passa pelo crivo da tríade pode ser mostrado - pelo menos é o corpo feminino mais recorrente na mídia em geral, e principalmente em anúncios publicitários. Assim a mídia pós-moderna apresenta cotidianamente à mulher e a quem mais assistir milhares de imagens com o modelo de corpo perfeito a ser desejado e copiado.

A imagem da mulher na publicidade e na mídia em geral torna-se um "possível inalcançável", justamente por haver inúmeros recursos disponíveis para esse alcance. Entretanto, nenhuma chance real de alcance, já que esse corpo não existe a não ser imaginariamente, na fantasia e no fetiche social.

Nas capas de revista (ou no interior de suas páginas), em embalagens de produtos, em outdoors e vitrines, ou na programação de alguma das grandes emissoras de televisão; lá está ela: a bonita e magra jovem mulher, uma das grandes marcas da publicidade brasileira, ou melhor, da mídia brasileira.

Novaes (2006) afirma que o corpo, através das telas da televisão, é virtual e bidimensional. E especificamente sobre o corpo mostrado através da publicidade, ela afirma: é um corpo "para sempre diante do seu olhar" (Novaes, 2006, p.215). É um corpo construído para ser olhado. Assim, as mulheres pós-modernas estão em busca de um corpo que seja, sobretudo, admirado pelo olhar do outro.

\section{Considerações Finais}

Tornar-se mulher significa se tornar sujeito através da cultura. Indiscutíveis são as diferenças biológicas e corporais existentes entre homens e mulheres. E também indiscutíveis são as posições sociais direcionadas a cada um deles na cultura ocidental.

Entretanto, consideramos que a discussão a respeito da formação subjetiva da mulher, referenciada dentro do paradigma tradicional está em condição de ser repensada. Considerar a condição fálica como paradigma universal e tratar a condição da mulher pós-moderna dentro dessa lógica talvez seja uma forma de negar a própria condição feminina e tomá-la como mero objeto, não de desejo, mas passível de ser adquirido como posse, como tantos outros, cuja medida de valor simbólico é o falo.
De qualquer forma, a cultura pós-moderna ainda se orienta, ou melhor, ainda possui a marca de 8.000 anos de patriarcado. A mulher pós-moderna ainda se orienta pelo referencial fálico, mas já se dá conta que isso não lhe basta. A castrada freudiana, invejosa e desejosa de um falo que lhe inscreva enquanto sujeito ainda se impõe. A noção de castração fálica, em Freud, leva a pensar que as mulheres convivem mais presentemente com a sensação de que "algo falta". Ainda que a falta seja uma condição humana, são as mulheres, a exemplo das antigas histéricas que são chamadas a denunciá-la, na medida em que recai sobre elas o silenciamento da condição feminina. Silenciamento esse que, apropriado pela mídia e cultura do consumo, podem constituí-la como um simulacro do feminino, através do consumo de adereços, próteses e infinitos produtos que a equiparam aos grandes modelos de mulheres, mas que não lhe garante nem a singularidade nem a resposta do que ela, mulher, realmente é ou quer.

A beleza, e todos os cuidados com a tecnologia corporal são compreendidos como uma das faces do falo à mulher, na cultura ocidental. Isso quer dizer que a beleza é compreendida enquanto uma forma de poder às mulheres. E também enquanto uma espécie de compensação à imperfeição, ou à condição de castrada. Ou seja, toda a tecnologia da imagem, empreendida pela mulher, acontece no sentido de propiciar-lhe a condição de esconder a falta constituinte (condição de castração), para permitir-lhe, a partir da sedução inerente à beleza, "buscar o que lhe falta".

Nesse sentido, concebemos que a beleza feminina é construída pelo Outro, atribuído enquanto mídia, no sentido de atrair o outro, já que acreditamos que a subjetividade feminina, sobretudo através do espetáculo, acontece no sentido de atrair o olhar do outro, ou melhor, de assegurarse na possibilidade de ser olhada pelo outro.

Talvez uma das grandes questões a que tratamos é compreender que a tecnologia da imagem, ou seja, todos os cuidados corporais tornaram-se, ao longo do século XX, produtos de consumo oferecidos às mulheres cotidianamente através dos diversos meios de comunicação em massa. Em outras palavras, a beleza - poder atribuído à mulher, tornouse uma imagem a ser assistida e copiada, destituída, assim, de possibilidade de singularidade.

\section{Referências}

Albuquerque, A. B. (2004). Produção de subjetividades, processos de subjetivação. In C. A. Peixoto Junior (Org.), Formas de subjetivação (pp.95-113). Rio de Janeiro: Contra Capa.

Araújo, D. C. (2006). O consumo e a mulher consumidora. Comunicação, Mídia e Consumo, 3(7), 147-165. 
Baccega, M. A. (2000). Comunicação/Educação: aproximações. In E. Bucci (Org.), A TV aos 50: Criticando a televisão brasileira no seu cinqüentenário (pp.95-109). São Paulo: Fundação Perseu Abramo.

Barreto, R. M. (2009). Publicidade e a produção de subjetividade. In CRP - Conselho Federal de Psicologia. Mídia e psicologia: Produção de subjetividade $e$ coletividade (2 ${ }^{\mathrm{a}}$ ed, pp.195-208). Brasília: Conselho Federal de Psicologia. Recuperado de www.pol. org.br/pol/export/sites/default/pol/publicacoes/ publicacoesDocumentos/livro_midia_psicologia final_web.pdf

Bauman, Z. (1998). O mal-estar da pós-modernidade. Rio de Janeiro: Jorge Zahar.

Bíblia Sagrada. (1980). Rio de Janeiro: Imprensa Bíblica Brasileira.

Birman, J. (1999). Cartografias do feminino. São Paulo: Editora 34.

Birman, J. (2001). Gramáticas do erotismo: A feminilidade $e$ as suas formas de subjetivação em psicanálise. Rio de Janeiro: Civilização Brasileira.

Bucci, E. (2000). Antropofagia patriarcal. In E. Bucci (Org.), A TV aos 50: Criticando a televisão brasileira no seu cinqüentenário (pp.111-131). São Paulo: Fundação Perseu Abramo.

Carreteiro, T. C. (2005). Corpo e contemporaneidade. Psicologia em Revista, 11(17), 62-76.

Debord, G. (1997). A sociedade do espetáculo: Comentários sobre a sociedade do espetáculo. Rio de Janeiro: Contraponto.

Carvalho, N. (2007). Publicidade: A linguagem da sedução. São Paulo: Ática.

Fortes, I. A. (1998). Mulher e trabalho: Entre a melancolia e o luto. Revista Estudos Feministas, 6 (2), 286-303.

Freud, S. (1996). Algumas consequências psíquicas da distinção anatômica entre os sexos. In J. Strachey (Ed.), Edição Standard das Obras Psicológicas Completas de Sigmund Freud (Vol. 19, pp.271-286). Rio de Janeiro: Imago. (Originalmente publicado em 1925)

Freud, S. (1996). Sexualidade feminina. In J. Strachey (Ed.), Edição Standard das Obras Psicológicas Completas de Sigmund Freud (Vol. 21, pp.229-251). Rio de Janeiro: Imago. (Originalmente publicado em 1931)

Freud, S. (1996). Conferência XXXIII: Feminilidade. In J. Strachey (Ed.), Edição Standard das Obras Psicológicas Completas de Sigmund Freud (Vol.22, pp.113-134). Rio de Janeiro: Imago. (Originalmente publicado em 1933)

Ghilardi, M. I. L. (2002). A publicidade e a representação do feminino: Tradição e modernidade em anúncios dos anos 90. In M.I.L Ghilardi, \& V.H. Barzotto (Orgs.) Nas telas da mídia (pp.119-140). Campinas, SP: Alínea.

Goldenberg, M. (2005). Gênero e corpo na cultura brasileira. Psicologia Clínica, 17(2), 65-80.

Herrmann, F. (1999). O que é psicanálise - para iniciantes ou não... (13 ${ }^{\mathrm{a}}$ ed.). São Paulo: Psique.

Herrmann, F. (2004, Abril). Apesar dos pesares. Texto inédito apresentado como conferência na Sociedade Brasileira de Psicanálise de São Paulo, São Paulo.

Keh, M. R. (1998). Masculino/Feminino: O olhar da sedução. In A. Novaes et al., O olhar (pp.411-423). São Paulo: Companhia das Letras.

Kehl, M. R. (2000). Televisão e violência do imaginário. In E. Bucci (Org.), A TV aos 50: Criticando a televisão brasileira no seu cinqüentenário (pp.133-151). São Paulo: Fundação Perseu Abramo.

Kehl, M. R. (2003). Oespetáculo como meio de subjetivação. Recuperado de http://www.mariaritakehl.psc.br/PDF/ oespetaculocomomeiodesubjetivacao.pdf

LeBreton, D. (2006). A sociologia do corpo. Petrópolis, RJ: Vozes.

Mira, M. C. (2003). O masculino e o feminino nas narrativas da cultura de massas ou o deslocamento do olhar. Cadernos Pagu, 21,13-38.

Moreno,R.(2009). Publicidadeea produçãode subjetividade. In CRP - Conselho Federal de Psicologia. Mídia e psicologia: Produção de subjetividade e coletividade. (2a ed., pp.185-194). Brasília: Conselho Federal de Psicologia. Recuperado de www.pol.org.br/pol/export/ sites/default/pol/publicacoes/publicacoesDocumentos/ livro_midiapsicologia_final_web.pdf

Novaes, J. V. (2006) O intolerável peso da feiúra sobre as mulheres e seus corpos. Rio de Janeiro: Puc Rio.

Pagès-Delon, M. (1989). Le corp set sés apparences L'envers Du look. Paris: L'Harmattan.

Pondé, L. F., Tiburi, M. (2009). Filosofia na alcova [gravação audiovisual]. Recuperado de http://www. cpflcultura.com.br/site/2009/11/02/integra-filosofiana-alcova-com-luiz-felipe-ponde-e-marcia-tiburi/

Roza-Junior, J. A. (2009). As inter-relações na adolescência: A máquina in-corporada e a virtualidade contemporânea. Dissertação de Mestrado 
em Psicologia Aplicada, Universidade Federal de Uberlândia, Uberlândia, Minas Gerais.

Sodré, M. (2003). Televisão e psicanálise (2 ${ }^{\mathrm{a}}$ ed., Série Princípios). São Paulo: Ática.

Vigarello, G. (2006). História da beleza: O corpo e a arte de se embelezar, do renascimento aos dias de hoje. Rio de Janeiro: Ediouro.

\section{Endereço para correspondência:}

Christiane Moura Nascimento

Endereço: Av. Cesário Alvim, no 14, Ap. 1003, Centro.

Uberlândia-MG. - CEP: 38400-096

E-mail: christiane_mn@yahoo.com.br

\section{Endereço para correspondência:}

Luiz Carlos Avelino da Silva

Endereço: Universidade Federal de Uberlândia, Av.

Engenheiro Diniz, no 1178 B, Martins. Uberlandia/MG. -

CEP: 38400-902

E-mail: luizavelino@yahoo.com.br 